\section{ANALYSIS OF THE BLOOD IN}

\section{PHTHISIS PULMONALIS;}

Iis Treatment with Sulphuric Acid and Digitalis, and Muriate und Carbonate of Soda; And on Free Carbon in Arterial Blood.

\section{To the Editor of The LANCET.}

Sin,-Continuing my narrative of experiments upon the vital fluid, I trust that I shall be excused, should any errors of diction, or ambiguity of expression, occur. In my opinion medical practitioners should readily find pardon for such trivial errors, at least from their compeers, when we reflect on the anxiety and care with which they are constantly occupied in the discharge of their professional duties.

Upon the 31 st of July last, I was called to visit the coachman of one of my friends, who had formerly experienced several attacks of hæmoptysis and cough, though the expectoration was frothy, and in small quantity. He informed me that he generally felt reduced in strength by such attacks. He had lost several of his relations from phthisis pulmonalis.

At the above-mentioned date, I found his respirations to be thirty-eight, and his pulse ninety-five per minute. On using the stethoscope at the bottom of the stermum, at the epigastrim, and below the left clavicle, I discovered that the pulsations of the heart were distinct. In using this valuable instrument to ascertain the state of the respiration, I found that the respiratory sound was louder towards the lower portions of the lungs, by reason of the direct obstacle to the circulation of the air in those parts of the lungs. The bowels were not bound, nor had the disease made such progress as to be remarkable to non-medical observers, with the exception of the hurried respiration when using more than his accustomed exertion. Any inedical man, of ordinary talents and experience, could have detected the "fons et origo mali," - viz. tubercles of the lungs.

This appeared to me to be one of the best of cases for ascertaining the nature of the blood in tubercular lungs; for the patient lived in comfort, and was indulged to his heart's content. I had known him for several years, and was satisfied that none of the tuhercles had been wasted by discharge from the mouth; besides, the patient was in his 25th year, and every facility was afforded to me for my investigation of the blood.
I directed twenty ounces of blood to be taken from the arm of this patient, in vacuo, two ounces of which were immecliately submitted to analysis. To the eye this blood exhibited nothing worthy of particular remark. Fourtcen ounces contained one cubic inch of free carbonic acid gas.

Tho following results were obtained :-

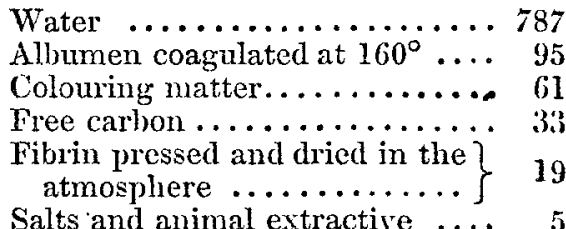

Salts and animal extractive .... 5

\section{0}

I candidly acknowledge, that from having found such excess of salts in the case of noli me tangere, not long ago recorded in the pages of THE LANCET, and considering the melting down, as it were, of the nose, to bear great similitude to the melting down of the lungs in tubercular phthisis pulmonalis, I expected to find excess of salts in the case just detailed. I kept a strict look-out for a case of a similar description, in order to discover whether a deficiency of salts might be considered as a prominent symptom in this most obscure and untoward disease, and I received the following case, which is just in point :-

On the 11th of this month (March), Richard Bird, a sailor, a native of Lowestoff, at. 24, became my dispensary patient. This young man had experienced two or three attacks of hrmoptysis, for which he was bled at the arm, and had used several medicines. At this moment his respiration is thirty-five, and his pulse one hundred and five per minute. The pulse is soft and feeble; his cheek is tinted with a hectic flush, and a gentle perspiration bedews the forehead; the bowels are generally regular; the respiration becomes hurried on his walking quickly, or on pressure upon the abdomen. He complains of languor, and reports that frequently he has transient pains of the chest when he has to climb the shrouds of the ship. He has never been troubled with purulent expectoration. $\mathrm{He}$ is (as well as the above-mentioned coachman) a very fine-looking young man, though he reports that he has fallen off in strength and flesh.

The stethoscope, ceteris paribus, gives me similar impressions to those which I observed in the case of the coachman. In a word, this young man has every symptom of tubercles of the lungs, and he reports that his mother died of this disease. 
I directed eighteen* ounces of blood to be taken from his arm; it was, in appearance, healthy.

These fourtcen* ounces of blood contained 1.44 cubic inch of free carbonic acid gas. The following were the results of the analysis of this blood :-

\begin{tabular}{|c|c|}
\hline ater & \\
\hline Albumen coagulated at $160^{\circ} \ldots$ & \\
\hline ig matt & \\
\hline bon .. & \\
\hline $\left.\begin{array}{l}\text { ressed and dried in the } \\
\text { phere } \ldots \ldots \ldots \ldots \ldots\end{array}\right\}$ & \\
\hline
\end{tabular}

1000

On comparing the results of these ana. lyses, we find a wonderful similarity as to the constituents of the blood of these young men. The deficiency of salts, in both cases, is most remarkable.

Some years ago I learnt, from the valuable and interesting experiments of the enlightened Dr. Orfila of Paris, that so far from vegetable or mineral acids destroying the soporific virtues of opium and its several preparations, as formerly generally supposed, a contrary effect was produced by them when used at or soon after the administration of opium under any form. Many years ago I put this to the test of experiment, and, in my opinion, M. Orfila is perfectly correct. Knowing the virtues of acidum sulphuricum dilutum, and also of digitalis purpurea, in phthisis pulmonalis, I resolved to try these valuable remedies in all stages of this formidable disease, and the following is the formula which I devised many years ago, and continue to employ in this disease:-

\section{R Tincture digitalis, et}

Acidi sulphurici diluti, a a seme drachmam; misce; fiant guttæ, quarum sumat guttas viginti ter in die e cochlearis quinque aquxe communis.

In some instances $I$ order a daily increase of the dose, one drop; in others two drops, till $70,80,90$, or 100 drops be the maximum dose of these compound drops. In some cases I direct double the quantity of the tincture, and vice versa, regulating it according to the presence of colliquative perspiration or diarrhcea, quickness or slowness of pulse, debility or excitement of the system.

I have always found that these two estimable medicines have their virtues increased when I employ them in this manner, and the same is well known to many professional men in this place, who are in

* Sic in MS. $-\mathrm{Ev}, \mathrm{L}$. the habit of following this plan of treatment in consumption of the lungs.

From what I have just stated, we are now, I humbly conceive, compelled to take into considcration how far we may attempt to coax the hlood (if I may be permitted the term) to take in a proper and proportionate supply of salts ju phthisis pulmonalis, and whether such attempt would be followed by all we desire to accomplish.

In this disease we generally find, that digestion and assimilation are seldom to he complained of, and therefore we are not to be afraid that, on using considerable portions of common salt and carbonate of soda, we shall be attempting what nature denies, as in typhus fever, or any other species of fever in which we find that the powers of digestion and assimilation are suspended for the time being.

I need scarcely remark to your enlight. ened readers, that other appropriate remedial measures, so as not to interfere with the due administration of these drops, ought to be employed at the same time, for subduing this untoward disease. In $\mathrm{my}$ present train of investigation, I hope "ere long," to be enabled, through the pages of The Laxcer, to throw some glimpses of light upon the proximate cause of phthisis pulmonalis.

Bonner, of whose case I gave some account in The LANCET for the 3rd of November last, applied at the Dispensary on the 7 th of this month (March) for my advice. I found that he had experienced a return of the symptoms, of which I made mention formerly, and was materially relieved by venesection on the 18 th of June last. Your readers will remember, that in the renous blood taken at that time, I found 32 per thousand of free carbon. I now directed the temporal artery to be opened, and $\mathrm{Mr}$. Penman abstracted eight ounces of arterial blood.

I submitted this blood to the process for extracting the free carbon, as formerly detailed in the case of the same individual recorded in the pages of ThE LANCET. This renders the affair more interesting. Though these experiments occupied me three hours, with all the care and attention I could bestow, I could obtain only two grains of free carbon per thousand. Frorn this we find, that arterial blood contains only a small proportion of free carbon, which we may suppose to he left in the blood for contingencies after pulmonary circulation. How wonderful the provisions afforded by such arrangement!

In the same week Mary Thompson, ætat. 45, widow, had blood to the extent of twenty ounces abstracted from the temporal artery, for excess of blood in the head. I found on analysis, that this arterial blood contained three per thousand of free carbon. 
In conclusion I beg to remark, that both these persons were very effectually relieved by this method of treatment. I remain, Mr. Editor,

Your most obedient servant,

W. Reid Clanny.

Sunderland, March 30th, 1833.

\section{A S E S}

ILLUSTRATIVE OF THE SANATIVE

EFFECTS OF THE

HYDROCYANIC ACID.

By Richand Lanyon, M.D., Lostwithiel.

The opinion expressed in the eleventh volume of The LANCET (page 588), that the hydrocyanic acid in pectoral diseases has been much overrated, and, in consequence, has fallen into disrepute, and almost disuse, so entirely agrees with my own, that I trust no apology will be required for my calling attention to the result of my experience in the use of this valuable remedy.

Case 1.-A young widow, disposed to hysteria, had for some time been afflicted with gastrodynia. From a minim and a half to two minims of the hydrocyanic acid every eight hours, afforded permanent relief. Eight doses only were taken.

Case 2.-A young woman, whose case resembled the preceding, excepting that the weakness and sinking at the scrobiculus cordis were excessive, was treated just as successfully with the acid, and in similar doses.

Case 3.-A lady who had suffered much from inanition, arising out of an attack of menorrhagia rubra, was suddenly seized with pain at the scrobiculus cordis, shooting to the back and shoulders. Tongue moist, but having a white fur, vitiated taste, nausea, flatulence, and bowels disposed to constipation. Without attending to the state of the bowels, she was directed to take a minim of the acid every eight hours, and with complete success.

Case 4.-A very delicate girl, between twelve and thirteen years of age, much disposed to phthisis, whose mother died of that disease, was suddenly attacked with diarrhœa, owing to fright, which was restrained by the usual means. Is pale and emaciated, with occasional hectic flushes. No dyspnoea at any time, but has a dry cough, occasioned by a titillation referable to a spot just above the pit of the stomach. Has had pain at the pracordia, but that has disappeared; inspires freely and fully, without cough; tongue dry, with a dark fur; does not perspire at night; sleeps well generally; appetite good; pulse weak, and ninety. Feeling confident that this cough was symptomatic of gastric disease, I did not hesitate to treat it as such. $A . H . \eta$ lss ter de die. I found the day after, that she had taken two doses, and harl passed a restless night, with almost incessant coughing. A.H. $\mathrm{mj}$ ter de die. On the third day the report states, "spirits and muscular power much improved; slept well last night, and has coughed but little since yesterday. Pergat." From this time the tongue gradually cleansed, and convalescence was soon established.

Case 5,-A child, fifteen months old, the subject of acute bronchitis, had, subsequently a troublesome dry cough. The eighth of a drop of hydrocyanic acid every eight hours removed the cough, and was followed by the expulsion of several lumbrici. I am not prepared to say on the authority of a single case, that the acid possesses unequivocal enthelmintic properties, although Professor Brera extols it as possessing such properties. Dr. Brown Langrish, in his experiments with the lauro-cerassus, and Dr. Elliotson, have both noted its vermifuge tendency, but this is the only case of the kind which has occurred to me.

Case 6.-A man of phlegmatic temperament had an attack of acute rheumatism, with threatened retrocession to the chest. The usual means overcame this disposition, but left a very troublesome cough, so that he could not lie in bed nor take any rest. Mucous expectoration, streaked with pus; pulse 70 and calm. Digitalis, colchicum, and various means, were ineffectually had recourse to ; I therefore determined to try the effect of the hydrocyanic acid. $A . H$. $m j$, ter de die. The next day he is reported as much the same. R Acidi hydrocyanici mix; Aqua zov, Mf.; two dessertspoonfuls every eight hours. After, this, the paroxysms became less frequent and less severe. The dose was now raised to two minims, and the cough soon subsided.

Case 7.-A very delicate woman, whose urinary organs had been deranged for many months, and whose case had been mistaken for carcinoma uteri, had, among other symptoms, a very obstinate cough at the hour of rest, when getting into the horizontal position, but during the day she was free from this troublesome complaint. A minim of the acid taken several nights in succession, half an hour before hedtime, relieved her permanently.

Case 8.-A female, retat. 36, far advanced in utero-gestation of her first child, was afflicted with very distressing palpitatio cordis, and although it had existed several montbs, and had of late become much ag. 